
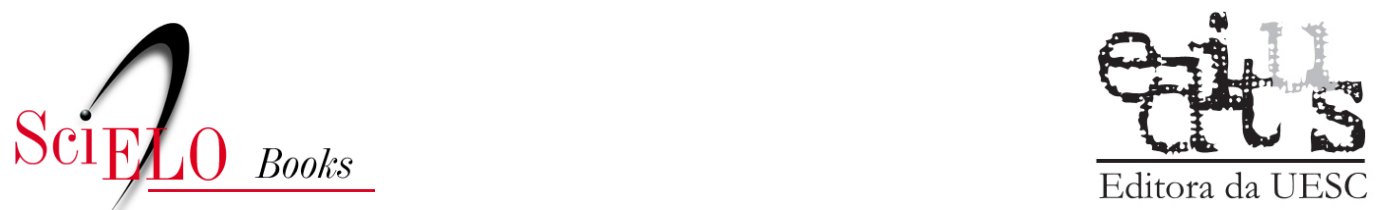

\title{
Idosas no contexto da vida cotidiana como percebem o corpo
}

\author{
Raimunda Silva d' Alencar
}

\section{SciELO Books / SciELO Livros / SciELO Libros}

D'ALENCAR, R. S. Idosas no contexto da vida cotidiana: como percebem o corpo. In: D'ALENCAR, R. S., ed. A representação social na construção da velhice [online]. Ilhéus, BA: EDITUS. 2017, pp. 147-170. ISBN: 978-85-7455486-0. https://doi.org/10.7476/9788574554860.0008.

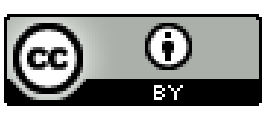

All the contents of this work, except where otherwise noted, is licensed under a Creative Commons Attribution 4.0 International license.

Todo o conteúdo deste trabalho, exceto quando houver ressalva, é publicado sob a licença Creative Commons Atribição 4.0.

Todo el contenido de esta obra, excepto donde se indique lo contrario, está bajo licencia de la licencia Creative Commons Reconocimento 4.0. 


\section{IDOSAS NO CONTEXTO DA VIDA COTIDIANA: COMO PERCEBEM O CORPO}

Raimunda Silva d' Alencar

Para entender que maturidade e velhice não são decadência, mas transformação, temos de ser preparados para isso (LUFT, 2010, p. 127).

\section{Introdução}

A palavra corpo, que vem do latim corpus, corporis, significa substância, matéria. O termo traduz um conceito complexo, que permite enriquecer a abordagem interdisciplinar sobre envelhecimento. A pluralidade de olhares possibilita compreendê-lo a partir das múltiplas dimensões que abarca, permitindo uma construção complexa dos processos que nele se desenvolvem e das percepções que constroem pessoas idosas em torno do próprio corpo ou em torno de si. Sem dúvidas, é uma das grandes preocupações humanas, apresentando-se como a identidade de cada um que, embora pertença ao indivíduo, é a sociedade quem o define e determina o jeito de apresentá-lo, cuidar dele, mantê-lo, protegê-lo.

Nesse sentido, não se pode imaginar a questão do corpo sem encará-lo como produto de uma construção 
histórica; mas não se pode esquecer de que é produto, também, de uma essência humana especifica, que vivencia situações específicas, em lugares determinados. Trata-se de uma realidade que é, ao mesmo tempo, subjetiva e social; é privada e é pública, é produzida pela sociedade, mas é, também, produzida pelo sujeito, ao produzir significado e sentido. Os processos simbólicos decorrentes ocorrem, portanto, na interação entre essas diferentes dimensões, o que significa dizer que não ocorre no vazio.

Envolvido nas emoções produzidas pelo sujeito, o corpo se emancipa como ponto de referência no espaço e no tempo, transformando-se em essência, substrato da identidade e, por extensão, da personalidade. Considerado por Barboza (2013, p. 3) como "cenário inafastável que fornece elementos onde se desenvolve o processo de construção" de cada um, é também produto de experiências onde se cristalizam a formação psíquica, protege-as como uma armadura específica, e alicerça-as.

O corpo é instrumento de realização, mas, também, de transgressão; é difusor de satisfação, mas, também, de dor; base de sensação, mas também de percepção e cognição; além de ser, também, instrumento de normatização de políticas públicas, por meio da Organização Mundial da Saúde (OMS), por exemplo, quando estabelece o envelhecimento ativo, conceito que tomou como base os principios de independência, participação, dignidade, assistência e autorrealização, amplamente defendido.

As emoções são consideradas o primeiro sistema de comunicações do ser humano, que compartilham com o corpo a motricidade, a sensibilidade e a sensualidade, representando uma linguagem privilegiada de rupturas e ligações com o ambiente, seja ele humano ou físico.

Desde muito cedo, aprendemos que corpo e alma são coisas distintas, que devem ser olhadas de modo independente, separadas, como se fossem dois mundos, um subordinado e escravizado pelo outro. As chamadas dores 
da alma sempre assumiram um grau de superioridade em relação às dores do corpo. Enquanto a alma era compreendida como a dimensão que representa a presença de Deus na vida humana, aquilo que é forte, que é perene, aquilo que fala de cada um, que não está visivel, o corpo, ao contrário, é aquela dimensão sensível que pode ser observada, tocada, tem visibilidade desde o nascimento à maturidade e a morte. Esse corpo ganha significados importantes como o lócus das paixões, do sofrimento e da dor, a fonte do erro, dos desejos e pecados, portanto, representa o símbolo da vitalidade, do vigor e altivez, mas, também, da fraqueza e fragilidade humanas.

Considerando essa polissemia do corpo e suas múltiplas funções, a pesquisa realizada buscou compreender as representações que as idosas constroem sobre seus próprios corpos, os componentes afetivos e cognitivos ligados à compreensão e percepção do corpo, bem como identificar o conceito que essas pessoas têm sobre corpo ideal, e como os significados que constroem sobre o corpo afetam as práticas cotidianas de autocuidado.

Para analisar essas construções e percepções, foi utilizada como referência a teoria da Representação Social, por considerar que os processos que engendram as representações envolvem não só a comunicação, mas as práticas sociais e culturais por elas desenvolvidas cotidianamente. Essas concepções se originam nos significados que cada uma dessas idosas elaboram no dia a dia a respeito do próprio corpo, refletindo uma dupla dimensão, de produção social e de produção subjetiva. 
A pesquisa contou com a participação de 22 idosas com idades que variaram de 60 a $88 \operatorname{anos}^{1}$. A seleção ocorreu através da explicitação da proposta em uma sala de aula com alunas matriculadas nas atividades da UNaTI-UESC, que se manifestaram motivadas a participar do trabalho. Foram realizados cinco encontros com o grupo, durante cinco semanas, cujo propósito foi direcionar as entrevistas, a partir de quatro aspectos de abordagem:

- o corpo nos espaços e tempos cotidianos, aqui compreendendo os espaços privados (relacionados à casa e às atribuições diárias como dormir, acordar, comer, cuidar, delegar, fazer) e público (relacionados à rua, como trabalhar fora, desenvolver ações voluntárias, comprar, vender, visitar, divertir, estudar);

- o aspecto pessoal, como vestir, maquiar, higienizar, estabelecer relações;

- situações/fatos que afetaram ou afetam seus corpos;

- como vê o próprio corpo e o que significa um corpo ideal.

Nesses encontros, e para abordar um dos aspectos elencados anteriormente, foi utilizada a técnica de grupo focal. Trata-se de técnica qualitativa de (re) coleção de informações baseadas em entrevistas coletivas, realizadas em grupos homogêneos. No primeiro encontro foi feita a apresentação da proposta com os presentes na reunião e já iniciada a abordagem sobre a visão que temos sobre o corpo e como o usamos e cuidamos dele. Nos demais encontros, nas semanas seguintes, foram tratados os demais aspectos elencados acima.

1 Vinculadas à Universidade Aberta à Terceira Idade da Universidade Estadual de Santa Cruz (UnATI - UESC), nas seguintes faixas de idades: 32,4\% entre 60 e 65 anos, 22,7\% entre 66 e 70 anos e 45,5\% a partir de 71 anos. 


\section{Falando de representação social e corpo na velhice}

Para falar de representação social é preciso lembrar Émile Durkheim, que inaugura, no campo da sociologia, o termo Representação Social ${ }^{2}$. Atualmente é um conceito que aparece ligado a todos os domínios das ciências humanas, situando-se no centro de um conjunto de noções ou múltiplos conceitos, como imaginário, ideologia, mito, mitologia, utopia e memória (MAKOWIECKY, 2003).

Durkheim faz uma distinção entre o estudo das representações individuais, pertencente ao domínio da psicologia, e o estudo das representações coletivas, ao da sociologia. O fundamento de tal distinção estava na crença de que as leis que explicavam os fenômenos sociais não eram as mesmas leis que explicavam os fenômenos individuais (FARR, 1995).

Assim, as representações coletivas, por serem fruto dos acontecimentos sociais, se constituem em fato social e, como tal, é resultado de uma consciência coletiva e não de uma consciência individual. Essa é a razão pela qual, segundo Durkheim, não se pode tratar as representações coletivas numa perspectiva individual.

O debate iniciado por Durkheim sobre representações coletivas foi crucial para Moscovici que buscou, na sociologia, um contraponto para a perspectiva individualista da psicologia social. Entretanto, Moscovici (1978) defende que a representação social, não a representação coletiva, deve

2 Etimologicamente, o termo 'representação' provém da forma latina 'repraesentare' - 'fazer presente' ou 'apresentar de novo'. Fazer presente alguém ou alguma coisa ausente, mesmo uma ideia, por intermédio da presença de um objeto (FALCON, 2000). Já para Jovchelovitch (1997), a noção de 'representação' era sinônimo de cópia, de espelho do mundo. Representar era copiar ou reproduzir o social. Essa ideia influenciou, por longo tempo, as ciências sociais e a psicologia, dando a ilusão da coincidência perfeita entre o psíquico e o mundo. 
ser encarada "tanto na medida em que ela possui uma contextura psicológica autônoma como na medida em que é própria de nossa sociedade e de nossa cultura" (MOSCOVICI, 1978, p. 45). Para ele, a representação social "é uma modalidade de conhecimento particular que tem por função a elaboração de comportamentos e a comunicação entre indivíduos" (MOSCOVICI, 1978, p. 26).

Abordar o corpo em envelhecimento na perspectiva da Representação Social significa trazer para o debate um conjunto de significações construídas e apropriadas no processo cotidiano de uma velhice em construção. Considerando que os idosos necessitam se apropriar da realidade, é bom lembrar que eles se apropriam, também, dos aspectos estigmatizados dela.

Para compreender a realidade, apropriando-se de ideias e valores circulantes, não é possível separar a razão da emoção, o subjetivo do cognitivo, bem como o individual do social, sendo imprescindivel analisar a fala do idoso com o apoio de elementos que estruturam as representações construídas no cotidiano, naquilo que faz parte da vida de todos os dias, através da convivência que o senso comum possibilita, integrado que está à vida do dia a dia, e que funciona no sentido de interpretar, pensar e agir sobre a realidade. Trata-se, portanto, de um conhecimento prático que se opõe ao pensamento científico.

É comum a percepção da velhice vinculada a aspectos negativos e à homogeneização, como se todos envelhecessem da mesma maneira, tivessem a mesma história de vida e vivessem as mesmas situações, nas mesmas circunstâncias. Não se tem levado em conta que os padrões de envelhecimento e as qualidades da experiência de envelhecer dependem da interação de muitos fatores, que incluem circunstâncias histórico-culturais, intelectuais e de personalidade, e refletem as condições materiais de vida, os condicionamentos individuais e da própria sociedade onde se encontram. 
Considerados um peso e um problema para o Estado brasileiro, inclusive para as famílias, os velhos continuam marginalizados, apesar de muitas mudanças. Embora não se tenha dúvida de que o prolongamento da vida representa ganhos, tem sido comum que a longevidade seja considerada uma ameaça, um grande desafio para toda a sociedade, nas suas múltiplas dimensões.

Ainda que parte da sociedade brasileira esteja mais sensivel às questões que dizem respeito à velhice e ao envelhecimento, as representações sociais ainda negativas continuam sendo construídas, apropriadas e reproduzidas em toda a sociedade, por todos os segmentos sociais e, até mesmo, pelo próprio velho. Não se pode negligenciar o fato de que as nossas ideias e pensamentos são organizados de acordo com um sistema que está condicionado pela cultura.

Apesar dessa sensibilidade, só os velhos sabem que não é fácil ser velho no Brasil, onde quem não produz de acordo com as normas de mercado não tem lugar nem espaço e onde direitos e oportunidades iguais não existem para todos. Ao longo da história econômica e social brasileira, o trabalhador nunca foi valorizado, nem mesmo como cidadão, cujos direitos lhe foram sistematicamente negados (COSTA; CAMPOS, 2009). Hoje, na condição de velho e perdida a oportunidade de continuar produtivo, a afirmação de Bosi (1994, p. 81) é emblemática: "o velho não tem arma. Nós é que temos de lutar por eles".

Ao analisar a questão estrutural das representações sociais, Jean Claude Abric (1998, p. 28) considera que elas respondem a quatro funções: a função de saber, quando permite aos atores compreender e explicar a realidade por meio da aquisição de saberes práticos do senso comum, coerente com a capacidade cognitiva e os valores a que aderem esses atores; a função identitária, quando define a identidade e permite que a especificidade do grupo seja protegida; a função de orientação, quando guia os comportamentos e as práticas, definindo o que é lícito, tolerável 
ou inaceitável em um dado contexto social; finalmente, $\underline{a}$ função justificadora, quando permite preservar e justificar comportamentos e práticas que podem contribuir para a diferenciação social, estereotipar relações entre grupos, discriminar ou manter distância social entre eles. Essas funções dão a medida da importância das representações sociais na orientação de condutas e práticas sociais e no sentido de investigação de como se formam e funcionam as referências utilizadas para classificar pessoas e interpretar acontecimentos da realidade, decorrente das relações com a linguagem, a ideologia e o imaginário social.

O que é importante assinalar é que a teoria das representações sociais trata da produção dos saberes sociais, aqueles que se produzem no cotidiano e que pertencem ao mundo vivido (JOVCHELOVITCH, 1997). Por pertencer à concretude da vida, ela permite a interpretação do mundo, facilita a comunicação e orienta as ações e comportamentos. Em outras palavras, a representação é uma construção do sujeito enquanto sujeito social e enquanto indivíduo, devidamente contextualizado.

\section{3 discurso das idosas na construção da representação do corpo}

o corpo é também o que dele se diz e aqui estou a afirmar que o corpo é construído, também, pela linguagem. Ou seja, a linguagem não apenas reflete o que existe. Ela própria cria o existente e, com relação ao corpo, a linguagem tem o poder de nomeá-lo, classificá-lo, definir-lhe normalidades e anormalidades, instituir, por exemplo, o que é considerado um corpo belo, jovem e saudável (GOELLNER, 2003, p. 29).

O interesse pontual pela questão do envelhecimento representa, sem dúvidas, um aspecto positivo para toda a 
sociedade, que reconhece as demandas que o incremento de anos à vida vem estabelecendo. Com a longevidade cada vez mais crescente, maiores e mais qualificados conhecimentos exige esse segmento populacional.

Ainda que continue sendo vista como peso econômico, do ponto de vista social, a velhice é olhada, também, pelo corpo que apresenta, mais especificamente pela debilidade fisica, que no imaginário social quase sempre se associa à debilidade cognitiva. Trata-se, portanto, de mecanismo depreciativo e discriminatório, que confere às pessoas idosas um significado que as diminui perante essa mesma sociedade, cabendo-lhes aceitar as categorias impostas, identificando-se com elas a fim de serem reconhecidas e de se reconhecerem (GOFFMAN, 1988), ou rejeitá-las, buscando e revelando mecanismos e estratégias para superar os modelos impostos.

\section{$3.1 \mathrm{O}$ corpo nos espaços e tempos cotidianos}

[...] Pois não somos só nossa aparência; mas somos também nossa aparência. Negá-la é negar o que, afinal, nos tornamos. Por isso, se é melancólico negligenciar a aparência, é patético querermos parecer ter 20 anos aos 40, ou 40 aos 70. Deveríamos querer ser belas, dignas, elegantes e vitais pessoas - de 60 ou 80 anos (LUFT, 2010, p. 91).

O corpo é aquela dimensão sensível que pode ser observada, que é visível, do nascimento ao definhamento e a morte, passando pelo crescimento. Também é considerado a sede do sofrimento e da dor, a fonte do erro, portanto, o símbolo da fraqueza humana. Já a alma era considerada mais nobre, porque considerada a dimensão propriamente humana, aquilo que faz o ser humano diferente de outros animais, ou da natureza de um modo geral. É o instrumento por meio do qual o ser humano vivencia com o outro, ao mesmo tempo em que se socializa com o meio social. 
O corpo nos espaços e tempos cotidianos é o corpo do dia a dia, é o corpo de todas as horas. O cotidiano, conforme o dicionário Aurélio (FERREIRA, 1995, p. 184), é definido pelo que é "diário, de todos os dias". O significado simples dessa palavra esconde toda uma complexidade de ações e práticas, saberes, características que estão inseridas na vida cotidiana. Como diz Michel de Certeau (1998, p. 31), é "aquilo que nos é dado cada dia". E o que nos é dado?

Estudiosa do cotidiano, Agnes Heller (2000, p. 17) faz a análise teórica sobre a vida de todos os dias e enfatiza que a vida cotidiana "é a vida de todo homem", "é a vida do homem inteiro", ou seja, todos estão inseridos em um cotidiano, fazem parte dele, com a individualidade de cada um. O cotidiano é a história vivida por todos e por cada um, partilhada e compartilhada.

As idosas deste estudo deixaram claro que no seu dia a dia há uma multiplicidade de ações e rotinas no que diz respeito ao aspecto pessoal (higiene, vestuário, maquiagem), ao espaço da casa (varrer, lavar, passar, cozer, rezar) e da rua (trabalhar, fazer compras, ir à igreja), desde o momento em que acordam. Deixam claro que essas ações e rotinas não se separam, ainda que possam estabelecer horários para realizá-las.

O importante é assinalar que os fazeres cotidianos geram corpos e estratégias de produção desses fazeres, que tanto podem estabelecer códigos de como ser e parecer, de como vestir, descansar, mas, até mesmo, higienizar e alimentar.

Isso posto, é cada vez mais imperativo saber como se organiza um corpo em uma ordem social que pressiona, exige, cria demandas, ameaça, desestrutura, confunde, traz insegurança, estressa, violenta. De um lado, essa ordem social produz corpos deprimidos, em pânico, depressivos, viciados, cansados, sem forças, feridos, amassados, drogados, machucados, compulsivos, sem respostas para as dúvidas e incertezas cotidianas. De outro lado, 
essa mesma ordem produz corpos conectados, sarados, erotizados, esculpidos, explorados, mercantilizados, que malham, que dançam, que andam na moda, que ditam moda, corpos que são capazes de estabelecer novos recordes ("beijei tantos homens ou tantas mulheres", "fiz sexo tantas vezes hoje, na semana, com tantos homens ou tantas mulheres", "trabalho xis horas por dia"), corpos que se transformam no centro das atenções e sonho de consumo (ainda que para isso tenham que passar por sacrificios).

Partindo dessas concepções, verifica-se que inserir a questão do corpo de pessoas idosas como tema de estudo implica um olhar sobre a vida diária dessas pessoas, atravessadas por problemas de várias ordens, que têm regras e organicidade estruturadoras do dia a dia, regras essas que se manifestam na organização da vida privada, do descanso, da troca, como quer Heller (2000), complementadas com as regras para o autocuidado, para a manutenção da funcionalidade fisica e cognitiva, pela obrigatoriedade de uma velhice ativa, como estabelece a medicina.

Merleau-Ponty (1999, p. 269) assinala que

quer se trate do corpo do outro ou de meu próprio corpo, não tenho outro meio de conhecer o corpo humano senão vivê-lo, quer dizer, retomar por minha conta o drama que o transpassa e confundir-me com ele. Portanto sou meu corpo, exatamente na medida em que tenho um saber adquirido e, reciprocamente, meu corpo é como um sujeito natural, como um esboço provisório de meu ser total.

É ainda Merleau-Ponty (1999, p. 227) quem afirma que "se o corpo pode sinalizar a existência, é porque a realiza e porque é sua atualidade". A propósito dessa afirmação, é interessante observar o que diz Stefano Rodotà (apud BARBOZA, 2013, p. 9), quando põe em pauta as seguintes indagações: "de quem é o corpo? Da pessoa interessada, de sua família, de Deus, da natureza, da sociedade que dele se 
apropriou, de um médico ou de um juiz que lhe estabelecem o destino?" Além disso, de qual corpo se fala?

Para a primeira pergunta, pegamos a afirmação de Studart (1990, p. 34), dizendo que "o nosso corpo nos pertence" pelas possibilidades que ele oferece, de percepção do mundo, de descobertas, de identificação, de subjetivação e de vivências. No entanto, e embora seja a partir dele que construímos, interagimos, trocamos, somos, conhecemos, confirmamos, negamos, ficamos, fugimos, fingimos, encontramos, desencontramos, essa autonomia é apenas aparente (D'ALENCAR, 2007, p. 21).

A segunda pergunta, não menos dificil que a anterior, evidencia a presença de vários corpos, que transcendem o corpo biológico, que vão do social ao psicológico, do corpo político ao jurídico. Todos esses corpos apresentam dupla expressão: uma real, que é o corpo físico, que está presente em determinado momento e lugar, e uma virtual, que transita com a transmissão de dados e para a qual não há limites de tempo ou espaço. Na verdade, afirma Heloisa Barboza, é possivel que o corpo virtual não tenha qualquer vínculo com o real, na medida em que pode ser "criado" pela própria pessoa ou por terceiros, com características totalmente distintas do corpo físico existente (BARBOZA, 2013, p. 9).

Sant' Anna (1997, p. 276-277) ao analisar a condição do corpo humano na história, afirma que estudá-lo "[...] é uma forma de descobrir, junto a todas as regras e coações, a emergência de liberdades e de prazeres outrora inexistentes".

Falar do corpo de pessoas idosas nos espaços e tempos do dia a dia é falar de ações e práticas inseridas na vida cotidiana, como o cuidado e a atenção pelo aspecto da aparência pessoal, o que faz para cuidar do corpo, desde a hora em que acorda. Uma das falas sugere descuido com o corpo em etapas pretéritas, revelando ao mesmo tempo que a velhice a despertou e a liberou para cuidar-se mais. 
- [...] Eu vim aprender a cuidar mais do meu corpo depois de uma certa idade. Hoje eu me cuido mais. Quando se é jovem tem muita coisa; não dá tempo nem se tem preocupação com isso $(E 1,72 a)$.

Atitudes renovadas têm significado o resultado de novas percepções, de novos sentimentos, de novas emoções. É que as mudanças, sejam psicológicas ou fisiológicas, caminham e acontecem juntas, alterando a nossa forma de pensar. É Nélida Piñon, escritora, quem afirma, em seu romance $A$ casa da paixão, que o corpo, uma vez inaugurado amorosamente, uma vez erotizado, altera o pensamento.

- Venho de uma família de obesos, diabéticos e cardíacos. Por isso, priorizei meu corpo. Faço ioga desde os anos 80 (quando ainda trabalhava no banco). .... Hoje não sinto nada. Pelos antecedentes, cuido da alimentação, que é a mais natural possível. Não fumo, não bebo (He, 67a).

$3.2 \mathrm{O}$ aspecto pessoal: vestir, maquiar, higienizar, estabelecer relações

As qualidades interiores vão sobressaindo, afirmando-se sobre as fisicas. Ao contrário da pele, cabelos, brilho de olhar e firmeza de carnes, elas tendem a se aprimorar: inteligência, bondade, dignidade, escutar o outro. Capacidade de compreender (LUFT, 2010, p. 90).

A construção social do corpo nos espaços e tempos cotidianos inicia-se já no nascimento, dada a contextualização desse momento. Nesse contexto, diz Heller (2000, p. 20), "a vida cotidiana não está fora da história, mas no centro do acontecer histórico: é a vida verdadeira essência da substância social", sendo por isso parte inerente à existência de todo e qualquer indivíduo. 
Com seu amadurecimento diário, que Heller (2000) denominou de "assimilação da manipulação", a idosa consegue viver o seu próprio cotidiano, aprendendo com o grupo a que pertence não só as artes de fazer como a de consumir. Aprende a manipular os objetos, instrumentos e a apoderar-se do uso social desses objetos, mas, também, aprende a apropriar-se de outras interações e a conviver com outros grupos, diferentes do seu originário, explicitando a beleza do corpo por uma aparência de efeito jovem (roupas, maquiagem, higiene).

- Sou muito simples quanto à minha maneira de vestir, sou desligada mesmo de usar produtos de beleza... (Mg, 71a).

Apesar das aprendizagens, não se pode minimizar o paradoxo vivido pelas idosas: de um lado, as possibilidades de prolongamento da vida: mais anos, mais meses, mais dias de vida; de outro lado, a rejeição sofrida pela não aceitação, por parte da sociedade, do benefício da longevidade. De um lado, pode estar liberada (ou não) do trabalho na rua (algumas das idosas trabalham em igreja, têm barraca na feira, ou estão em sala de aula) e, de outro envolvem-se diuturnamente com os serviços domésticos, cuidados dos filhos e netos, ainda dependentes das mães e avós.

\section{Situações/fatos que afetaram ou afetam seus corpos}

[...] sobre o corpo se encontra o estigma dos acontecimentos passados do mesmo modo que dele nascem os desejos, os desfalecimentos e os erros nele também eles se atam e de repente se exprimem, mas nele também eles se desatam e entram em luta, se apagam uns aos outros e continuam seu insuperável conflito (FOUCAULT, 1979, p. 22). 
Os sentidos humanos são treinados para perceber e decodificar essas marcas, além de classificar os sujeitos pelas formas como eles se apresentam corporalmente, pelos comportamentos e gestos que empregam e pelas várias formas com que se expressam.

O importante é considerar que esse corpo que revela cada idosa, que identifica cada uma, não é um corpo acabado; ele é provisório, é permanentemente modificado:

- [...] as rugas no rosto, as carnes flácidas das pernas. E claro, na medida em que os anos passam a gente encolhe mais (Cs, 89a).

As mudanças vividas cotidianamente, independente da idade e da posição social e condição étnica, econômica, social, religiosa, educacional são registradas no corpo, o que sinaliza a ideia de que o nosso corpo é um elemento em permanente construção, como o é cada sujeito. Como diz uma entrevistada,

- [...] agora é que estou percebendo o quanto mudei. Provavelmente murcharei mais ainda (Ra, 74a).

Dessa compreensão decorre a afirmação de Sant'Anna (2000, p. 237), para quem se o corpo não cessa de ser descoberto, é preciso não perder de vista a provisoriedade de cada conhecimento produzido a seu respeito: constantemente redescoberto, nunca, porém, completamente revelado (apud D'ALENCAR, 2007, p.29).

Considerando que cada sociedade em tempo histórico específico tem seu modelo de corpo, este modelo supõe uma referência a uma norma, a uma concepção de gestos, de códigos, de posturas. Assim, o corpo não pode ser pensado fora de um contexto social no qual se insere, ou isolado dele, o que significa dizer, também, que pensá-lo fora das relações tira-lhe a conotação natural, de algo dado, que está aí. O corpo não só (re) produz códigos e significados, mas 
é também por eles produzido. É de Goellner (2003, apud D'ALENCAR, 2007, p. 29) a afirmação de que

mais do que um conjunto de músculos, ossos, vísceras, reflexos e sensações, o corpo é também a roupa e os acessórios que o adornam, as intervenções que nele se operam, a imagem que dele se produz, as máquinas que nele se acoplam, os sentidos que nele se incorporam, os silêncios que por ele falam, os vestígios que nele se exibem..

O corpo, portanto, não é uma entidade já pronta, mas é datado historicamente. "[...] As relações, as práticas sociais, historicamente datadas que produzem, ao longo da vida, nossos sentimentos, nossas preferências, nossa aparência e nossa fisiologia” (SANT' ANNA, 1997, p. 279).

\section{Como vê o próprio corpo e o que significa um corpo ideal}

Os corpos são significados e ressignificados pela cultura; mas ao mesmo tempo são por ela alterados. Basta que olhemos o processo de mudanças no nosso próprio corpo, ainda que nossos desejos e necessidades estejam em dissonância com a aparência de nosso corpo.

- [...] não cuidei do meu corpo, e ele envelheceu mal (Am, 67a).

Os corpos não são, pois, tão evidentes como usualmente pensamos, tampouco as identidades são uma decorrência direta das "evidências" dos corpos, conforme a fala abaixo:

- O meu envelhecimento está acontecendo através de uma tomada de consciência. Tenho que exercitar a ponderação, o bom senso. Lutar com nosso principal inimigo: nós mesmos. As perdas serão inevitáveis, mas os ganhos também (Mc, 68a). 
Weeks (1995) lembra que o corpo é inconstante, que suas necessidades e desejos mudam. O corpo se altera com a passagem do tempo, com a doença, com mudanças de hábitos alimentares e de vida, com possibilidades distintas de prazer ou com novas formas de intervenção médica e tecnológica.

- corpo ideal é um dom de Deus. Graças a Deus até hoje estou inteira, apesar da decadência. Particularmente eu já vivi esse corpo ideal; com tudo inteiro. O que mais me entristece é ver o meu corpo morrendo aos poucos; não se pode parar as marcas do tempo; aceito tudo isso pacientemente e vou levando e vivendo ( $M G, 72 a)$.

É importante conhecer como determinada característica passa a ser reconhecida, passa a ser significada, como uma "marca" que define a identidade. Cabe perguntar, por exemplo, quais os significados que, nesse momento e nessa cultura, estão sendo atribuídos, por pessoas idosas, por exemplo, a um corpo tatuado, a um corpo de piercing, a um corpo musculoso, a um corpo encoberto ou a um corpo desnudado.

Mas ainda que se distancie do seu destino biológico, por força de intervenções as mais variadas, o corpo é talvez a mais eloquente expressão da individualidade, da autorreferência, do lugar que ocupa cada sujeito na hierarquia social, do lugar que ocupam determinados valores, como a religião.

- O meu corpo é instrumento da minha vida, do meu espirito. Zelo por ele no sentido de não me contaminar; não tenho vícios (Ná, 76a).

- [...] Tenho muito cuidado com meu corpo,.... uso cremes, gasto o que posso para usar e deixar minha pele macia. Faço meu cabelo toda semana em salão... Faço hidroginástica..... Só uso perfume frances. Gosto de mim, me amo, ... gosto de toalhas bem macias... (Cl, 68a). 
- Vejo-o como o nosso principal indicador. Através dele sabemos muito sobre nós. Atualmente conseguimos entender seus sinais e procuramos não abusar... É um grande aliado (Mc., 68a).

Tratado como objeto afetivo, o investimento nos corpos é fato para uma parcela das idosas da pesquisa, que afirmam exercitar-se diariamente com alongamento, ioga, RPG, esteira de massagens, caminhada, pilates, atividade física, hidroginástica.

Sodré (1996, p. 175) afirma que o corpo humano é posto em crise por uma ordem tecnocultural que o nega, seja quando lhe atribui uma fraqueza fundamental (remediável apenas pela tecnologia ergonômica e biomédica), seja quando o incita a superar-se por meio de práticas cujo ideal é tocar os limites do humano e vislumbrar o inumano, tanto na forma da máquina como do animal. Nessa ordem se inscrevem a clonagem, as próteses, a difusão de epidemias que resultam da transfusão de sangue, em um movimento chamado por José Gil ${ }^{3}$ (SANT'ANNA, 1997, p.253) de "desapropriação do corpo".

Hoje, é possivel que microcâmeras adentrem o corpo e enviem imagens do seu funcionamento instantaneamente, que cânulas sejam usadas para sugar gorduras localizadas, estabelecendo-se e definindo-se o padrão que se deseja. É o corpo humano que, confundindo-se com a máquina ou produzido por ela, produz um corpo tecnicamente moderno, um cibercorpo (D'ALENCAR, 2007, p. 23), "desapropriado" do seu dono.

As imposições de saúde, beleza, vigor, força, que a sociedade realça em relação aos corpos, são apropriadas pelas idosas da pesquisa, que procuram adequar-se aos critérios estéticos e higiênicos, por meio de cuidados físicos, exercícios, roupas, aromas, alimentos, adornos, como afirmam.

3 Filósofo, professor da Universidade de Lisboa. 
Esses variados processos inscrevem nos corpos marcas de identidade e, ao mesmo tempo, de diferenciação, mostrando que as representações sociais têm a função de interpretar a realidade que cerca as idosas desta pesquisa, orientando as suas atitudes, preservando as do grupo de pertencimento em relação a outros grupos, como quer Abric, citado anteriormente.

- Engordei, agora estou com problema de saúde.... mas já recuperando $(L O, 77 a)$.

O corpo não é nada mais do que uma ideia histórica, isto é, um simples produto de construção cultural da sociedade, uma entidade real, material, um substrato de cada uma dessas idosas. A representação do corpo tanto pode estar associado a uma necessidade produtiva, como pode associar-se à funcionalidade. Em ambos os casos pode-se vinculá-lo diretamente com a rentabilidade, seja ela financeira e/ou funcional.

- é o corpo que pode responder às necessidades; pode andar, não sentir dores... (Am, 67a).

- ... é aquele saudável (Lou, 69a)

- ... é corpo saudável que deve estar em sintonia com o cérebro, os sentimentos, as emoções (MG, 72a).

Assim, as idosas não escapam dos critérios estéticos e éticos que a sociedade estabelece como corpo ideal. Da mesma forma, o envelhecimento, associado à perda de prestígio e afastamento do convívio social, também está associado à gordurinha corporal ${ }^{4}$.

- Corpo ideal é o que tenho. Vejo como dádiva de Deus. Corpo perfeito é aquele que eu me vejo e me aceito, do jeito que está. Tenho que viver o tempo, o momento (Na., 72a).

4 "É feio, é triste mesmo ver-se uma pessoa obesa, principalmente se se tratar de uma senhora; toca às vezes as raias da repugnância” (apud PRIORE, 2000, p. 75) 
- Meu próprio corpo; eu estou bem com ele. Emagreci $15 \mathrm{~kg}$, apenas por ter reduzido o sal (Ar., 65a).

- Corpo ideal é o que tenho neste momento. ...... Vejo como um templo do espirito santo. Procuro não ingerir alimentos ruins; e mantenho uma alimentação saudável (He, 64 a).

- É aquele que proporciona saúde (qualidade de vida). Nosso corpo fisico, por exemplo, a partir dos 52 anos, quando começamos a escutá-lo, respeitá-lo e cuidá-lo tem correspondido de maneira bastante satisfatória (Mc, 66a).

Contrariando a afirmação de Barboza (2013), quando sugere a possibilidade de não haver relação do corpo real com o virtual, as idosas desta pesquisa estabelecem convergência entre o corpo ideal e o real, partindo do próprio corpo. A relação corpo ideal-corpo real é feita diretamente e aparece na saúde, no trabalho em casa e fora de casa, na religião, no lazer, mas, também, na indiferença que experimentam. Ao falar do próprio corpo, elas já não tratam de qualquer corpo, do corpo do outro, mas o próprio, o da sua vivência, da experiência que cada uma tem de si mesmo, da sua própria história, da sua própria vida.

\section{Considerações...}

Não se têm dúvidas de que a experiência de vivenciar o próprio corpo marca o ser humano do começo ao fim da vida. Embora seja uma experiência vivida por todos, não se trata de experiência homogênea. Ela é vivida diferentemente, de acordo com o contexto cultural em que se encontra esse corpo, da classe social a que pertence, da etnia e do próprio ciclo de vida.

As idosas se identificam a partir de múltiplos cuidados com seus corpos e, ao mesmo tempo, se diferenciam, mostrando que as representações sociais que constroem e/ou se apropriam, no contexto onde se encontram, respondem 
às funções assinaladas por Abric, conforme apontadas anteriormente: as idosas compreendem e reproduzem o que o senso comum concebe sobre os seus corpos, além de comportarem-se e praticarem atividades corporais de autocuidado dentro daquilo que é social e previamente esperado para a pessoa idosa. Embora pensem romper com os estereótipos que caracterizam a realidade comum do conjunto social, permeia o imaginário social.

Mas é, também, uma atividade mental que orienta as idosas a posicionarem-se em relação à importância e singularidade de seus corpos, no que toca a diferentes situações, objetos e fatos da vida cotidiana. 


\section{Referências}

ABRIC. Jean-Claude. A abordagem estrutural das representações sociais. In: MOREIRA, Antonia Silva P.; OLIVEIRA, Denize C. de. (Org.). Estudos Interdisciplinares de Representação Social. Goiânia: AB, 1998.

BARBOZA, Heloisa Helena. A pessoa na era da biopolítica: autonomia, corpo e subjetividade. In: Cadernos IHU ideias, ano 11, n. 194, 2013.

BOSI. Ecléa. Memória e sociedade: lembranças de velhos. São Paulo: Companhia das Letras, 1994.

CERTEAU, M. A Invenção do Cotidiano 1: artes de fazer. 2. ed. Petrópolis: Vozes, 1998.

COSTA, Filomena G; CAMPOS, Pedro H. Faria. Representação Social da Velhice, Exclusão e Práticas Institucionais. Revista Eletrônica de Psicologia e Politicas Públicas, v. 1, n. 1, 2009. Disponivel em: <www.crp09.org.br>. Acesso em: 15 jan. 2017.

D' ALENCAR, Raimunda S. Velhice e função social do corpo. In: Memorialidades, n. 7 e 8, jan./dez, 2007.

FALCON, F.J. C. História e Representação. In: CARDOSO, C.F; MALERBA, J. (Orgs.) Representações: contribuição a um debate transdisciplinar. Campinas, SP: Papirus, 2000 (coleção textos do tempo), p.20-48.

FARR, Rob. M. Representações sociais: a teoria e sua história. In: GUARESCHI, P. A; JOVCHELOVITCH, S. (Org.). Textos em representações sociais. 3. ed. Petrópolis: Vozes, 1995. p. 31-59.

FERREIRA, Aurélio Buarque de Holanda. Novo Dicionário Básico da Língua Portuguesa Folha Aurélio. Editora: Nova Fronteira, 1995. 
FOUCAULT, Michel. Microfisica do poder. Trad. R. Machado. Rio de Janeiro: Graal, 1979 (coletânea de artigos publicada exclusivamente no Brasil).

GOELLNER, Silvana Vilodre. A Produção Cultural do Corpo. In: LOURO, G. L. et al. (Org.). Corpo, Gênero e Sexualidade - um debate contemporâneo na educação. Petrópolis, RJ: Vozes, 2003.

GOFFMAN, E. Estigma: notas sobre a manipulação da identidade deteriorada. Trad. M. B. M. L. Nunes. 4. ed. Rio de Janeiro: Guanabara, 1988.

HELlER, A. O Cotidiano e a História. 6. ed. São Paulo: Paz e Terra, 2000.

JOVCHELOVITCH, Sandra. Vivendo a vida com os outros: intersubjetividade, espaço público e representações sociais. In: GUARESCHI, P; JOVCHELOVITCH, S. Textos em representações sociais. 3. Ed. Vozes, 1997.

LUFT, Lya. Perdas \& Ganhos. 35. ed. Rio de Janeiro-São Paulo: Editora Record, 2010.

MAKOWIECKY, Sandra. Representação - a palavra, a idéia, a coisa. In: Cadernos de Pesquisa Interdisciplinar em Ciências Humanas (PPGICH), n. 57, dez., 2003.

MERLEAU-PONTY, Maurice. Fenomenologia da Percepção. Trad. Carlos Alberto R. de Moura. São Paulo: Martins Fontes, 1999.

MOSCOVICI, Serge. A representação social da psicanálise. Tradução de Cabral. Rio de Janeiro: Zahar, 1978.

PRIORE, Mary Del. Corpo a corpo com a mulher - pequena história das transformações do corpo feminino no Brasil. São Paulo: Editora SENAC, 2000. 
SANT' ANNA, Denise Bernuzzi de. O corpo entre antigas referências e novos desafios. In: Cadernos de Subjetividades. São Paulo, v. 5, n. 2, p. 275-284, dez., 1997.

. Entrevista com José Gil. In: Cadernos de Subjetividades. São Paulo, v. 5, n. 2, p. 253-266, dez., 1997.

As infinitas descobertas do Corpo. Cadernos PAGU, 14, 2000, p. 235-249.

SODRE, Muniz. A Mutação Identitária. In: . Reinventando a cultura, a comunicação e seus produtos. Petrópolis: Vozes, 1996. p.169-180.

STUDART, H. Mulher, a quem pertence teu corpo? Petrópolis: Vozes, 1990.

WEEKS, Jeffrey. Sexuality and its discontents: meanings, myths and modem sexualities. Londres: Routledge e Kegan Paul, 1995. 